\title{
Upper plate reverse fault reactivation and the unclamping of the megathrust during the 2014 Northern Chile earthquake sequence
}

\section{Geological background}

In our previous studies in northern Chile, we have identified at least 30 trench oblique reverse faults (Allmendinger et al., 2005; Allmendinger and González, 2010). Because the nature of these reverse faults is central to our interpretation of the $\mathrm{M}_{\mathrm{W}} 6.7$ foreshock to the Pisagua earthquake, we include short description of these reverse faults.

These reverse faults crop out in a $250 \mathrm{~km}$ long segment of the Coastal Cordillera running from Quebrada Camarones in the north $\left(19.2^{\circ} \mathrm{S}\right)$ to just south of the Río Loa $\left(21.6^{\circ} \mathrm{S}\right)$. On the eastern side of the Coastal Cordillera, reverse faults produce fault propagation folds affecting the Cenozoic infill of the Central Depression. Along the coastline, E-W reverse faults deform Quaternary marine terraces. The paleoseismology of these upper plate faults is poorly known so we use the Bajo Molle Fault as a proxy for the behavior of the all trench orthogonal reverse faults in the area. Exposed in a sea cliff at the southern limits of the city of Iquique, the Bajo Molle Fault thrusts Mesozoic volcanic rocks on top of Holocene marine sediments dated using Optical Stimulated Luminescence (OSL) (Figure S1). We estimate a cumulative Holocene uplift and horizontal shortening of $3.8 \pm 0.1 \mathrm{~m}$ and $1.3 \pm 0.1 \mathrm{~m}$, respectively, based on the deformation of a sand bed affected by a fault propagation fold. Using the OSL age we estimate an uplift rate of $0.38 \pm 0.02 \mathrm{~m} / \mathrm{ka}$, horizontal shortening rate of $0.135 \pm 0.015 \mathrm{~m} / \mathrm{ka}$ and net slip rate of $0.4 \pm 0.1 \mathrm{~m} / \mathrm{ka}$. Assuming a slip rate of $0.4 \mathrm{~m} / \mathrm{ky}$ and 1.0 $\mathrm{m}$ of coseismic slip, consistent with the moment magnitude of 6.7 , we can extrapolate a 2,500-year recurrence interval of upper plate earthquakes similar to that of the Pisagua earthquake sequence, representing approximately 25, 100-year subduction zone earthquake cycles. 


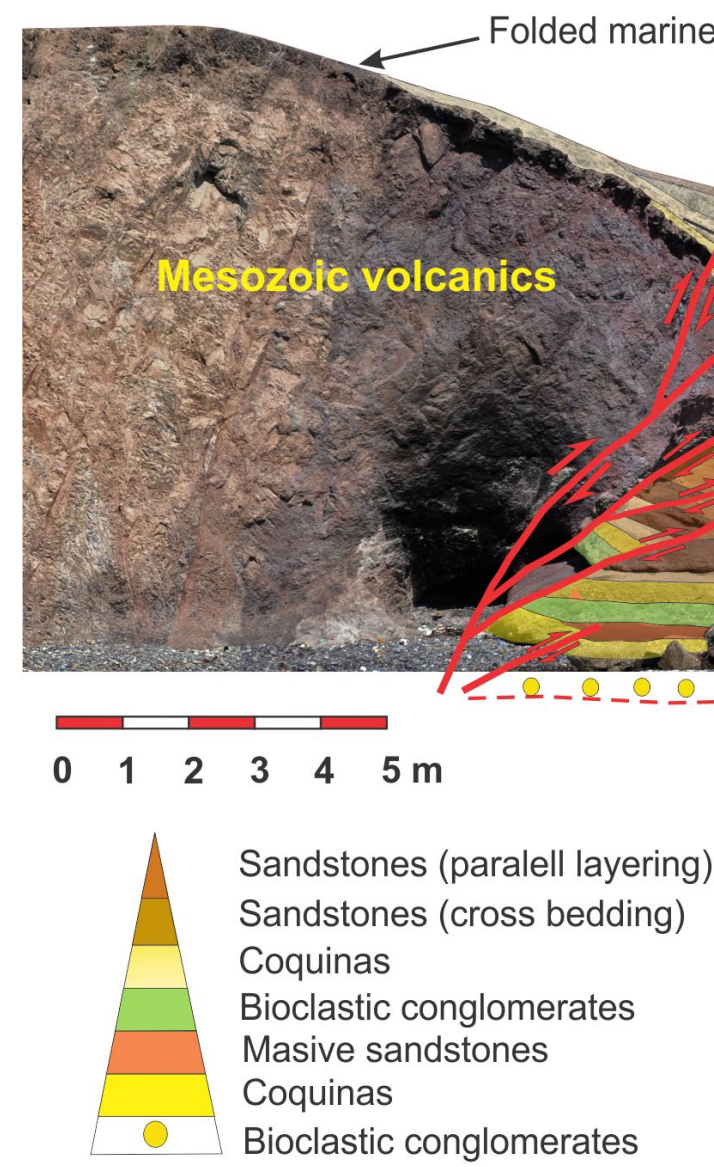

Transgressive facies 1
$9.28+/-0.98 \mathrm{ka}$ $10.87+/-1.29$ ka

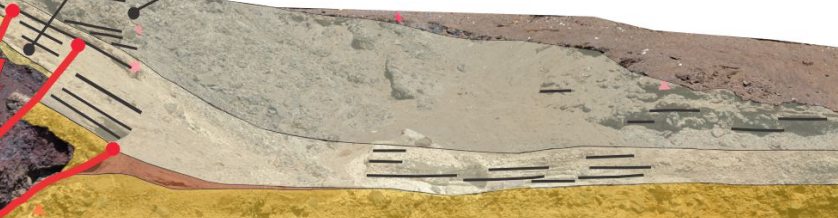

Mesozoic volcanics

Projected unconformity (faulted marine terrace in FW)

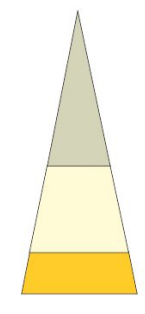

Matrix supported conglomerates

Bioclastic sandstones and coquinas

Bioclastic conglomerates

Transgressive facies 2

Figure DR1. Vertical section crossing the E-W reverse Bajo Molle Fault, view to the east of outcrop located at the southern part of Iquique. Red lines represent reverse faults with E-W strike. The faults exposed in this outcrop thrust volcanic Mesozoic rocks on Quaternary marine sediments. Red dots mark the position of fault tip-points. Marine sediments in the footwall (FW) define two transgressive facies. The black dots mark the position of OSL samples used for constraining the age of the uppermost marine horizons. These two marine horizons form a progressive unconformity related to fault propagation folding. The $24 \mathrm{~m}$ net fault slip is marked by the offset of unconformity separating the Mesozoic volcanic rocks from the Quaternary marine sediments.

\section{METHODS}

\section{Analysis of upper plate seismicity at $21^{\circ} \mathrm{S}$}

By using the NonLinLoc package and applying a 2D velocity model (Lüth, 2000) we determined the hypocenters of upper plate micro-earthquakes. The focal mechanisms were calculated using a high accuracy quality criterion, well-located events $(r m s \leq 0.2)$ and a minimum of 7 unambiguous $P$-wave polarities. According to the procedure described by Snoke (2003) in the FocMec software, not only were the focal mechanisms calculated based on the polarities of $P$-wave arrival, but the amplitude ratios of $S V / P, S H / P$ and $S H / S V$ were also used. The amplitude ratios were measured after a filter of 1.0-5.0 Hz and a rotation of the horizontal components of the seismogram were applied. The $S V$ and $S H$ amplitude ratios were hand-picked on the vertical or radial component, in the case of the $S V$, and transverse components for the $S H$ (Kisslinger et al., 1982). 


\section{Earthquake relocation}

We use local network data to construct a catalog of the Pisagua Earthquake Sequence by relocating 336 events that occurred between March 15th and April $4^{\text {th }}$, 2014, including foreshocks and aftershocks of the April $1 \mathrm{M}_{\mathrm{W}} 8.1$ Pisagua main shock. This catalog was compiled by manually picking $\mathrm{P}$ and $\mathrm{S}$ arrival times from waveforms collected from the European Mediterranean Seismological Centre (EMSC) catalog (for events $M>2$ ), and the GEOFON-GFZ catalog (for events $M>4$ ). We selected the waveform data from 8 broadband seismic stations of the Integrated Plate Boundary Observatory in Chile (http://www.ipocnetwork.org, 2014) located within $200 \mathrm{~km}$ of the epicenters of the $M_{w} 6.7$ and $M_{w} 8.1$ earthquakes. As a first step in locating these events, we used the probabilistic earthquake location code NonLinLoc (Lomax et al., 2000) with the 1D seismic velocity model of Husen et al. (1999). To further investigate the origin of the $M_{W} 6.7$ event and the subsequent migrating foreshocks leading up to the $\mathrm{M}_{\mathrm{w}} 8.1$ earthquake, we selected from the main catalog 192 earthquakes with magnitudes $M>2$ recorded between March 15-20. These events were relocated with the same $1 \mathrm{D}$ velocity model using the double-difference relocation algorithm HypoDD, which interrelates events that are closely clustered in time and space (Waldhauser and Ellsworth, 2000). From the 192 events, only 132 could be interconnected and therefore relocated by HypoDD. The HypoDD relocations show low average errors of $0.72,0.86$, and $1.41 \mathrm{~km}$ in the $\mathrm{x}, \mathrm{y}$, and $\mathrm{z}$ directions, respectively.

In Figure 2 of the main text, it is clear that events in the upper crust have larger depth location errors than interplate and intraslab events. The reason for this difference is that we use a 1D velocity model built for the analysis of aftershocks of the 1995 Antofagasta earthquake (Husen, 1999). The majority of these aftershocks were interplate and intraslab. Thus, the process for building the velocity model considered these events in the calculations and the minimization of the errors, resulting in a model with high resolution near the interface Nazca-South-American plates. Therefore, the model has less resolution for the events located in the upper crust. An implication is that the structure of the upper crust is more heterogeneous than represented in the Husen (1999) model. However, we use multiple techniques (e.g., HypoDD, waveform analysis) to prove that the events in the upper crust are not located on the subduction interface or within the slab. 

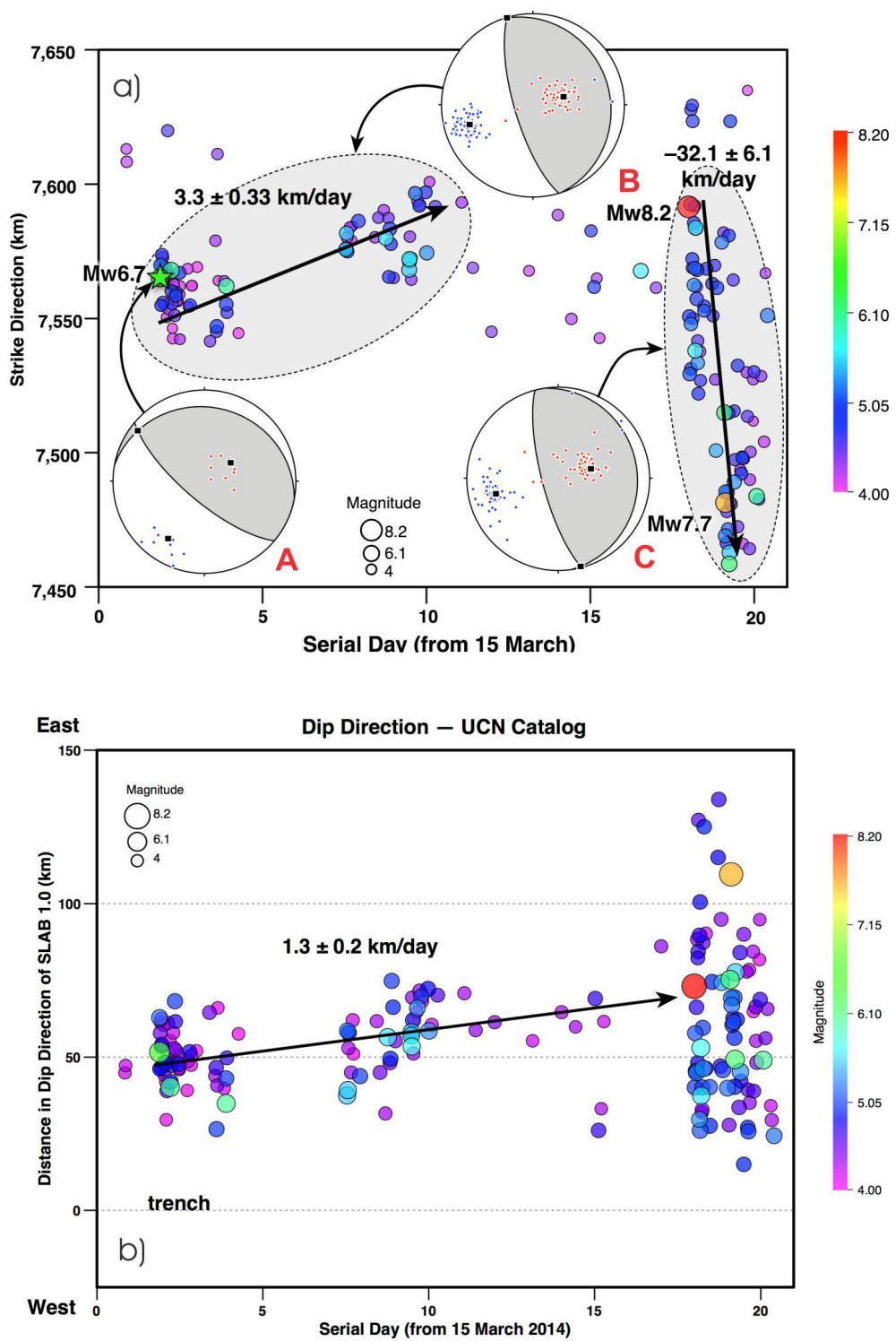

Figure DR2. a) Time series with events with $\mathrm{M}_{\mathrm{w}}>4$ from our catalog plotted versus distance parallel to the Slab 1.0 strike. Numbers on the vertical scale are UTM 19S coordinates transformed into parallelism with the strike (a $12^{\circ}$ counterclockwise rotation). Dashed ellipses identify the events used to calculate the least squares strikeparallel migration rate shown. Lower hemisphere equal area projections show the summed moment tensor principal axes and composite nodal planes for (A) the March $16 \mathrm{Mw} 6.7$ event and similarly oriented foreshocks, (B) the northward migrating cluster of foreshocks from day 2 to day 11, and (C) the Pisagua $\mathrm{M}_{\mathrm{w}} 8.1$ main shock and aftershocks recorded through day 20.5. Small red and blue dots in the lower hemisphere projections are the $\mathrm{T}$ and $\mathrm{P}$ axes, respectively, of the earthquakes used in the moment tensor analysis. b) Time series development of earthquakes in our catalogue plotted against distance down dip of the Slab 1.0 model geometry. The trench is located at $0 \mathrm{~km}$ on the $\mathrm{y}$-axis.

\section{Moment tensor Analysis}

Our moment tensor summations include all moment tensor solutions available from the USGS National Earthquake Information Center and the Global Centroid Moment Tensor catalog (U.S. Geological Survey, National Earthquake Information Center, http:// earthquake.usgs.gov (2014), Ekström et al., 2012). We sum the moments using standard 
techniques (Kostrov, 1974). Multiple solutions for a single earthquake have been averaged before being summed with other earthquakes. We use the program FaultKin by R.W. Allmendinger to calculate moment tensor sums available online. The program is available at: http://www.geo.cornell.edu/geology/faculty/RWA/programs/faultkin.html

\section{Waveform analysis}

The waveforms analyzed in this work correspond to the $100 \mathrm{~Hz} 3$-components from the IPOC stations PATCX, PSGCX, PB07 and PB08. Thus, this analysis is restricted to the near field and teleseismic waves were not used. For the inversion of the waveform, we used the ISOLA code (Sokos and Zahradník, 2008). The preliminary location for the $\mathrm{M}_{\mathrm{w}} 6.7$ was calculated by HypoDD method (Waldhauser and Ellsworth, 2000) and used as input in the ISOLA code.

Before the moment tensor inversion, the waveform velocity records were integrated once, in the frequency band of $0.08-0.2[\mathrm{~Hz}]$ with cosine tapering applied to both ends. Complete three-component waveforms are employed without separation of specific groups (e.g., P, S); these were re-sampled at all stations into 8192 points with a time-step of $0.15 \mathrm{~s}$ and duration of $245.76 \mathrm{~s}$. The wave inversion uses a 1D velocity model (Husen et al., 1999). The deviatoric point source inversion is selected for a series of trial source positions lying at various depths below the epicenter position determined previously.

Through a grid search over a set of trial source positions and time shifts, we seek the trial position and time for which the least-squares residual error between observed and synthetic seismograms is minimized. The search grid for the event inversion is shown in Figure DR3, the total trial sources tested were 15 , with a $2 \mathrm{~km}$ vertical separation, spanning depth from 2 to $30 \mathrm{~km}$. The best relation between seismogram correlation and double couple percentage was obtained in the trial source 7 to $14 \mathrm{~km}$ depth (Figure S4). This source is located at $14 \mathrm{~km}$ depth, with a time shift $+0.45 \mathrm{~s}$, a correlation of 0.5654 and a $99.7 \%$ of the double couple component. The solution of the moment tensor coincides very well with the solutions reported by USGS and GEOFON. The solution of the depth obtained by this analysis is consistent with the results obtained by the HypoDD method $(13.129 \pm 1.5 \mathrm{~km})$. Although the source 1 has a better correlation, its double couple percentage is very low and it is very different from the moment tensor solutions reported by USGS and GEOFON.

In summary, the results of the waveform analysis indicate that the $\mathrm{M}_{\mathrm{w}} 6.7$ Pisagua foreshock is well represented by a single source located at $14 \mathrm{~km}$ depth. 


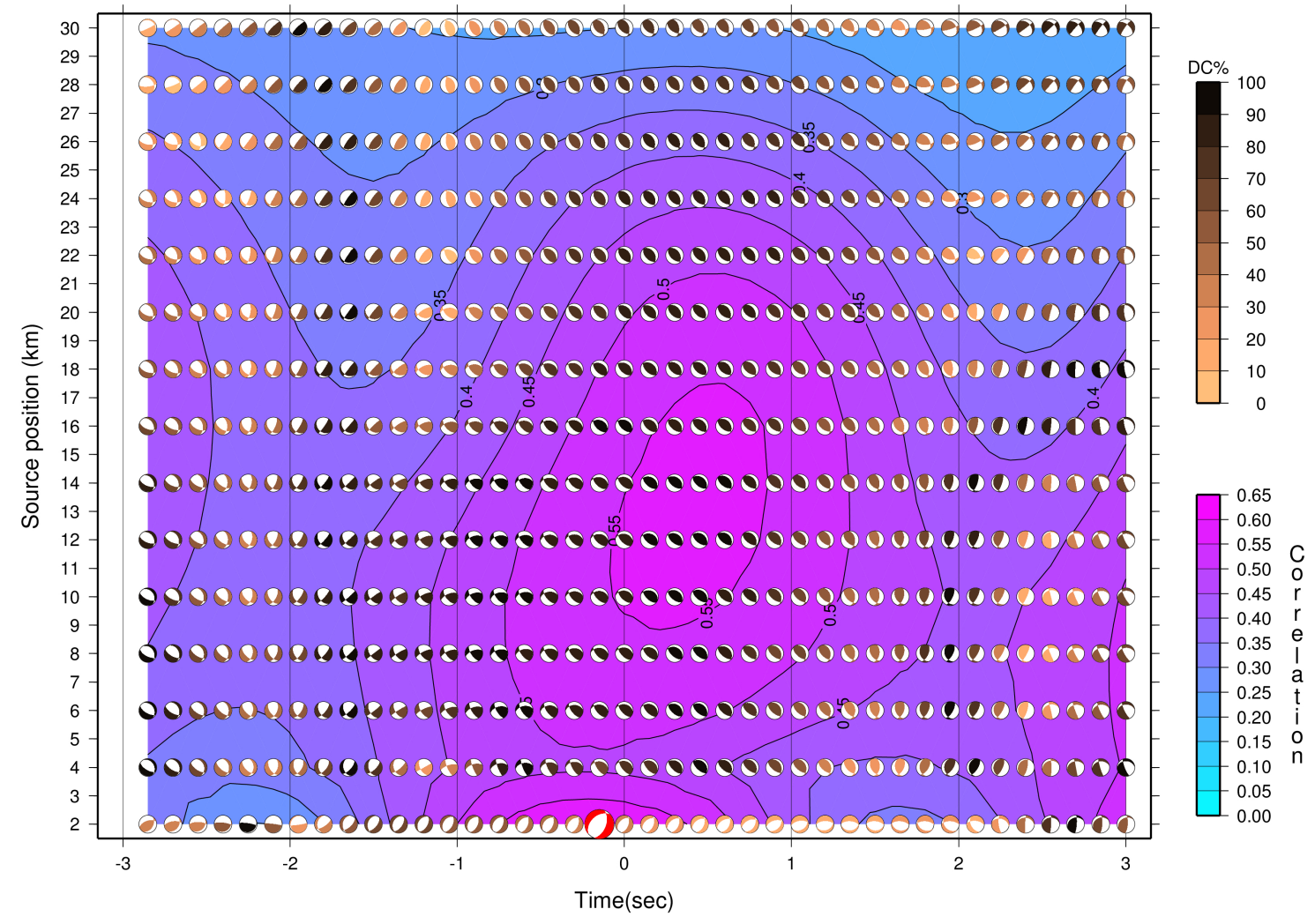

Figure DR3. Inversion parameters (correlation between observed and synthetic seismograms and double-couple percentage $(\mathrm{DC} \%))$ as a function of the trial source position and time.

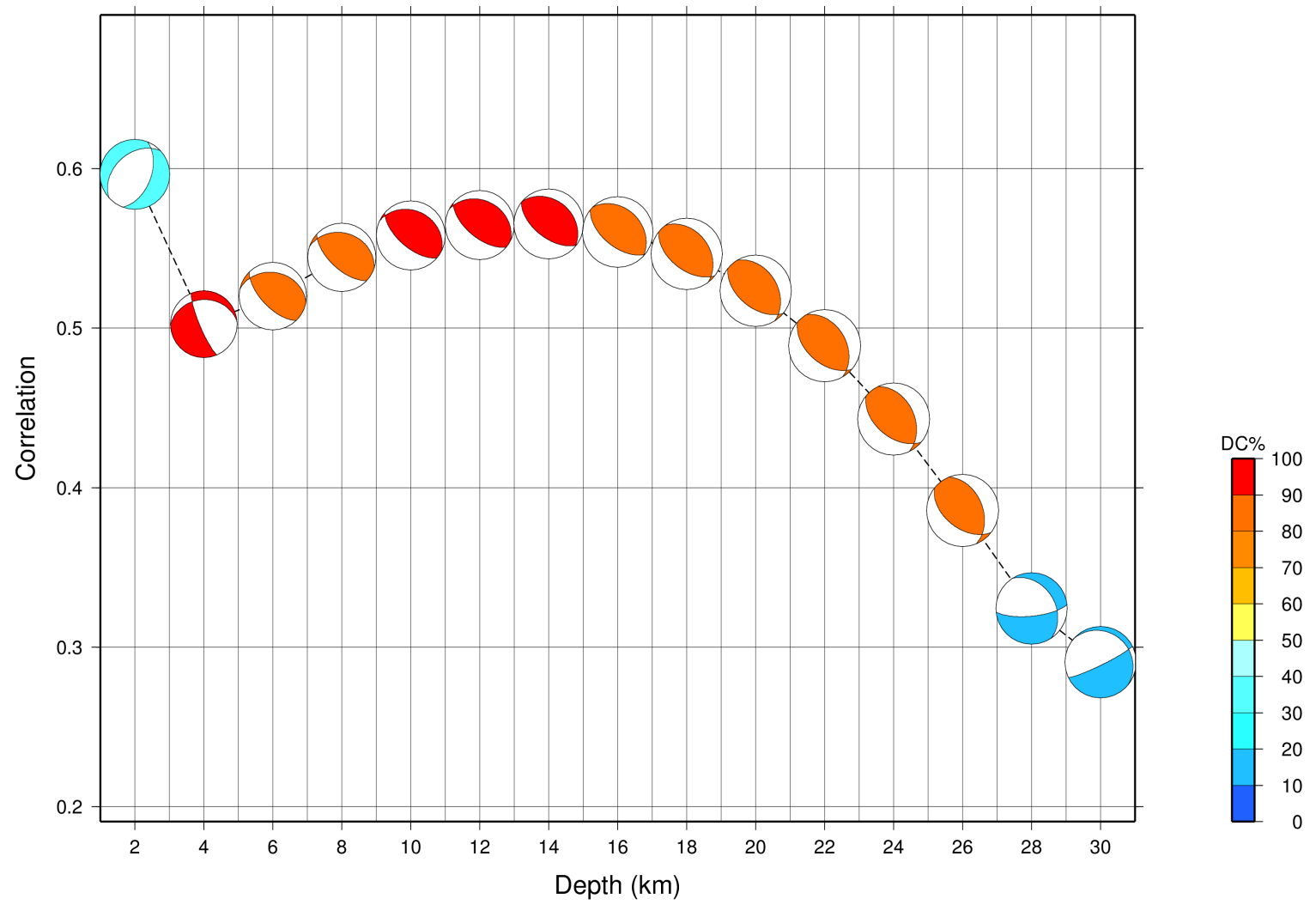

Figure DR4. Correlation between observed and synthetic seismograms as a function of depth and doublecouple percentage $(\mathrm{DC} \%)$. 

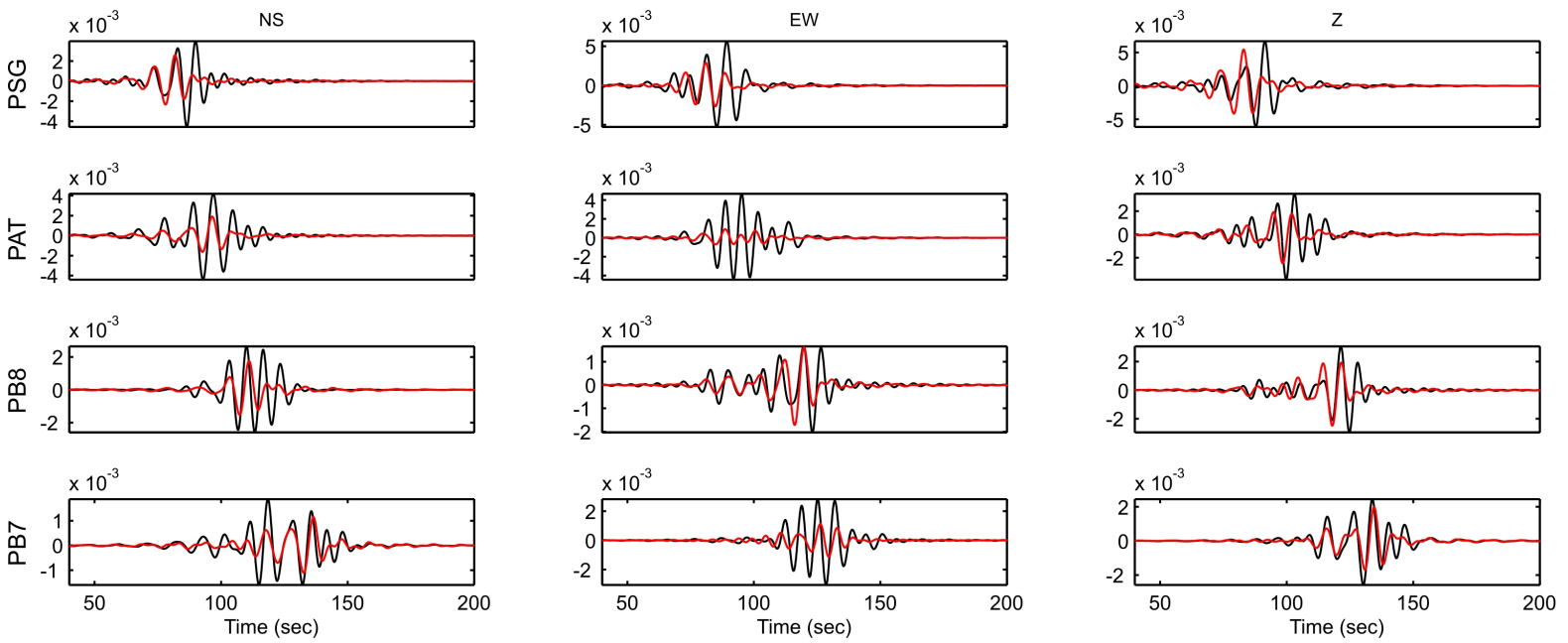

Figure DR5. Seismic waveform inversion for $M_{w} 6.7$ for the three components (NS, EW, Z) in the case of the IPOC stations PSG, PAT, PB7 and PB8. The red lines indicate synthetic and the black observed displacements through time.

\section{Stress change calculations}

We calculate stress change induced by earthquakes using elastic dislocation algorithms (Meade, 2007) relating slip to stress on triangular dislocation elements (TDEs). The megathrust is parameterized using TDEs with geometry based on Slab 1.0 (Hayes et al., 2012). For all calculations, we assume Lamé parameters of $3 \times 10^{10} \mathrm{~Pa}$ and a Poisson's ratio of 0.25 . For the $\mathrm{M}_{\mathrm{w}} 6.7$ event, slip in the direction of the estimated focal mechanism rake was applied across the modeled rectangular fault surface. We define Coulomb stress change, $\Delta \sigma_{\mathrm{CS}}$, as $\Delta \sigma_{\mathrm{CS}}=\tau_{\mathrm{dip}} \pm \mu ' \Delta \sigma_{\mathrm{N}}$, where $\tau_{\text {dip }}$ is the shear stress change in the dip direction (up-dip positive), $\Delta \sigma_{N}$ is the normal stress change (unclamping positive), and $\mu^{\prime}$ is the effective coefficient of friction on the fault surface, assumed to be 0.4 (e.g., King et al, 1994). Only where $\tau_{\text {dip }}$ is positive and of magnitude greater than the product $\mu{ }^{\prime} \Delta \sigma_{N}$ is $\Delta \sigma_{\text {CS }}$ positive. We calculate shear stress imposed on subduction interface in the local dip direction, consistent with the dominant kinematics of the earthquakes that occurred following the $\mathrm{M}_{\mathrm{W}} 6.7$ event. We show $\Delta \sigma_{\mathrm{CS}}$, as well as individual normal and shear components of stress change, for each nodal plane of the focal in Figures DR6-DR8.

We base cumulative stress change analyses on the locations of events in the NonLinLoc catalog from the March $16 \mathrm{Mw}_{\mathrm{w}} 6.7$ event to before the April $1 \mathrm{M}_{\mathrm{w}}$ 8.1 Pisagua earthquake. For each event, assumed to have occurred on the megathrust interface, we define a rectangular region based on the estimated moment magnitude using empirical scaling laws (Wells and Coppersmith, 1994), then select megathrust TDEs whose centroids lie within the horizontal projection of that rectangle. In cases of rectangles that formally contain no TDE centroids (due to element spacing and small earthquake size), we select the single TDE whose centroid is closest to the relocated hypocenter. Uniform slip in the dip direction is 
applied to the selected element(s), with slip magnitude guided by scaling laws (Wells and Coppersmith, 1994) and TDE area, such that the product of area and slip is proportional to seismic moment. Normal stress and shear stress in the local dip direction are calculated in this way for each earthquake in the relocated catalog, and then summed through time to yield the snapshots of cumulative stress change shown in Figure 3 and the supplementary figures.

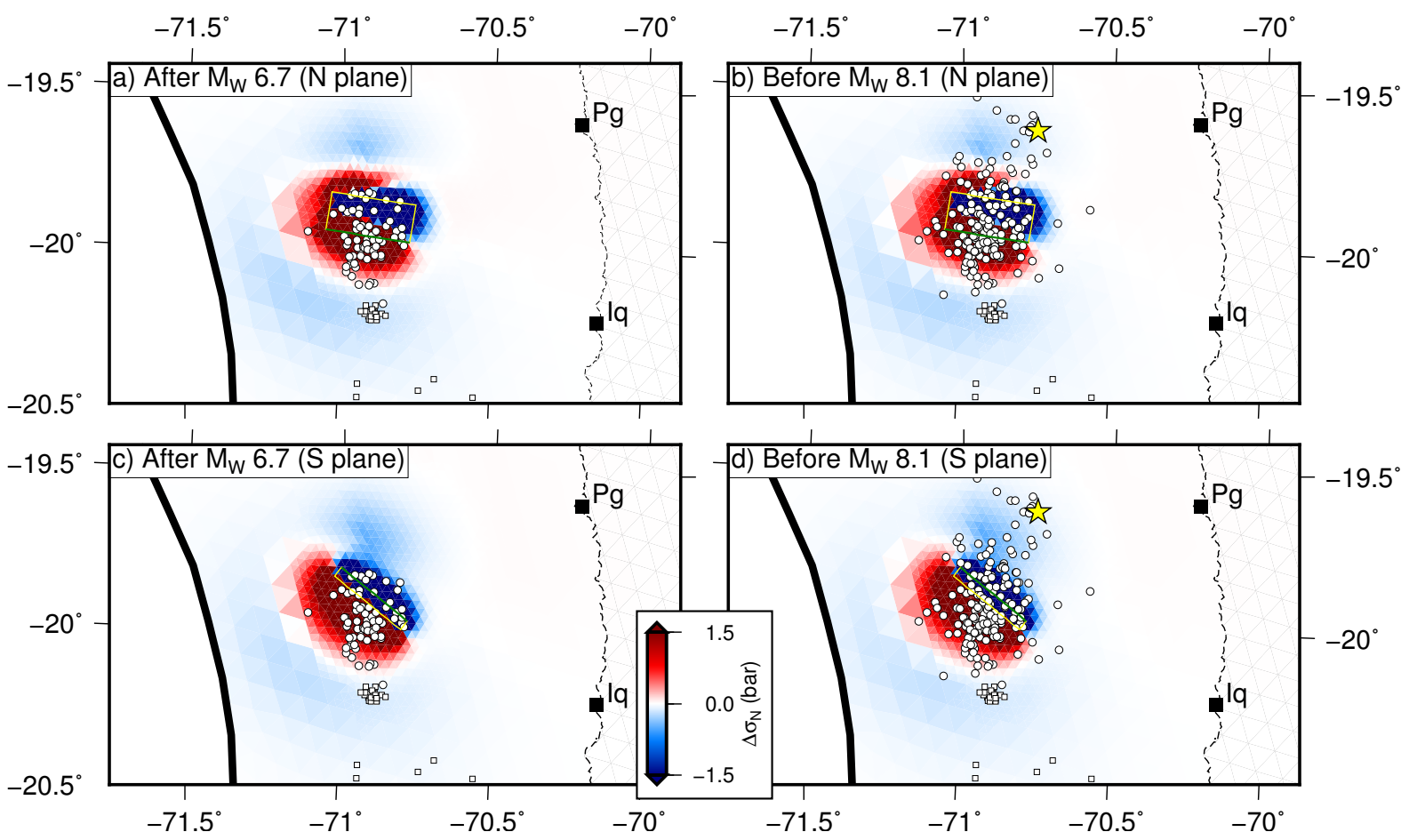

Figure DR6. a) Normal stress change induced on the megathrust by the Mw 6.7 crustal earthquake, using the shallow, north-dipping plane from the USGS Mww focal mechanism. Unclamping is taken as positive. b) Cumulative normal stress change on the megathrust from the crustal foreshock plus all subsequent foreshocks, up to the Pisagua earthquake mainshock. Panels $\mathrm{c}$ and $\mathrm{d}$ show the same results as a and $\mathrm{b}$, respectively, but use the steeper, south-dipping nodal plane for modeling the $\mathrm{M}_{\mathrm{W}} 6.7$ event. 


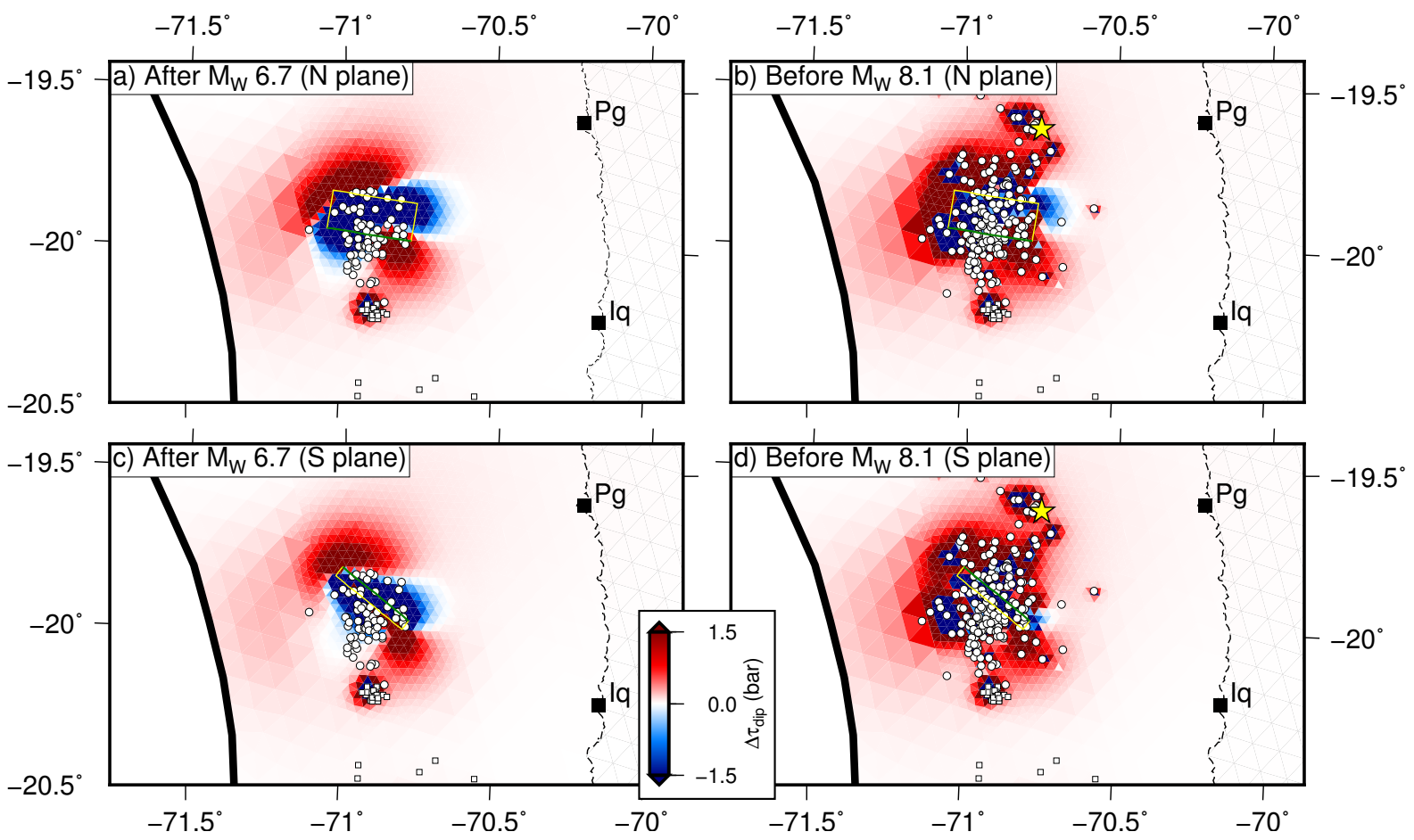

Figure DR7. Same as Figure DR6, but showing shear stress change induced on the megathrust (updip positive).

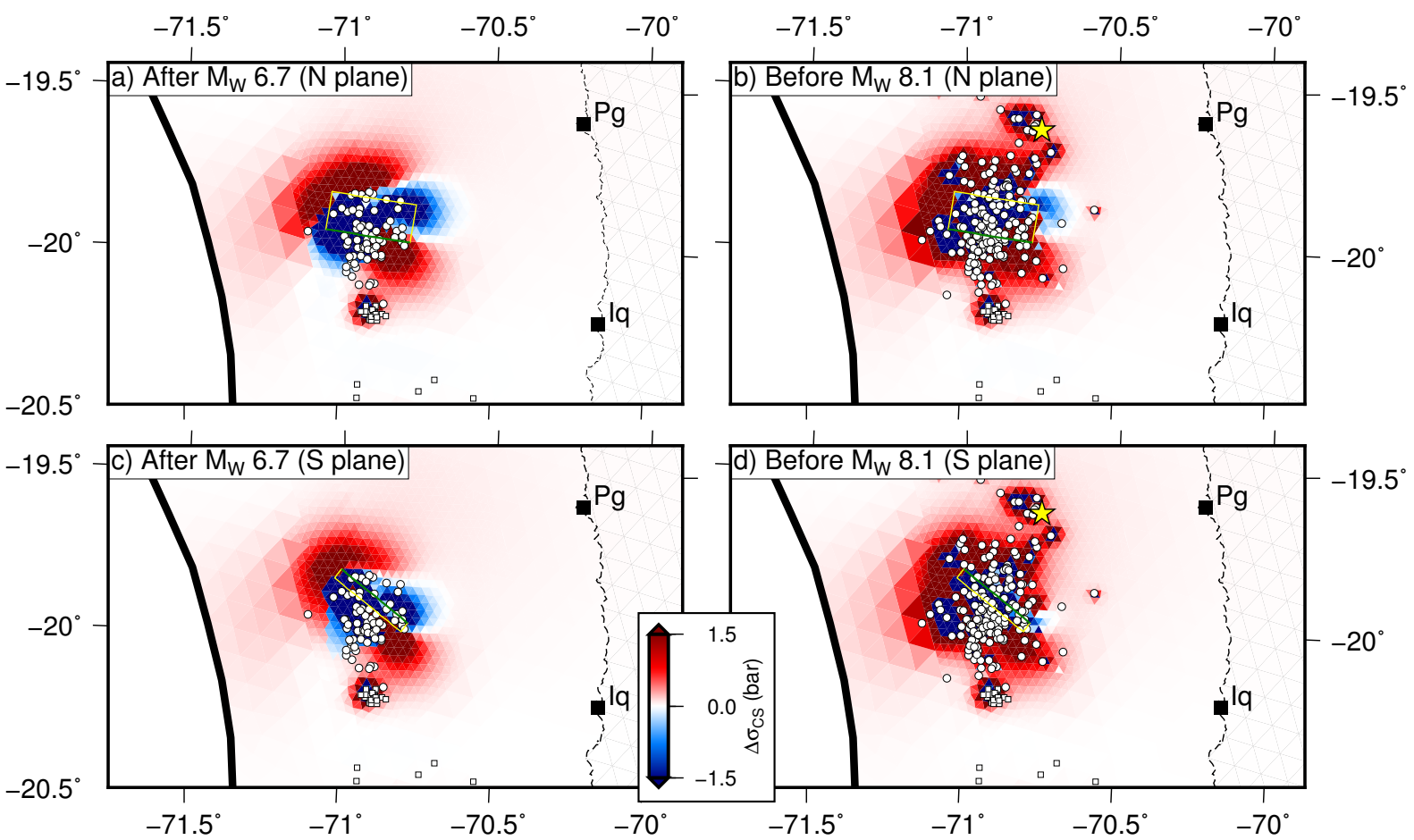

Figure DR8. Same as Figure DR6, but showing Coulomb stress change induced on the megathrust (updip shear and unclamping positive).

To compare earthquake locations to the stress change distribution, we find the element centroid closest to each relocated hypocenter as well as its immediately adjacent elements, and we find the maximum cumulative Coulomb stress change of those $\leq 4$ elements. Based on the cumulative stress change analysis, we find that $64 \%$ of foreshocks of the Pisagua earthquake correspond to positive stress change induced by slip on the north-dipping March 
16 nodal plane plus subsequent events, while $68 \%$ of all Pisagua foreshocks correspond to positive stress regions induced by slip on the south-dipping March 16 nodal plane plus later events (Figure DR9). We suggest that stressing of the megathrust as a result of slip on the upper plate fault facilitated the initial subsequent reverse faulting earthquakes on the megathrust, particularly given the presence of up-dip shear stress accumulated since 1877 . Then, earthquakes on the megathrust enhanced up-dip shear stress and positive Coulomb stress change along the strike and down the dip of the megathrust, eventually leading to the Mw 8.1 mainshock.
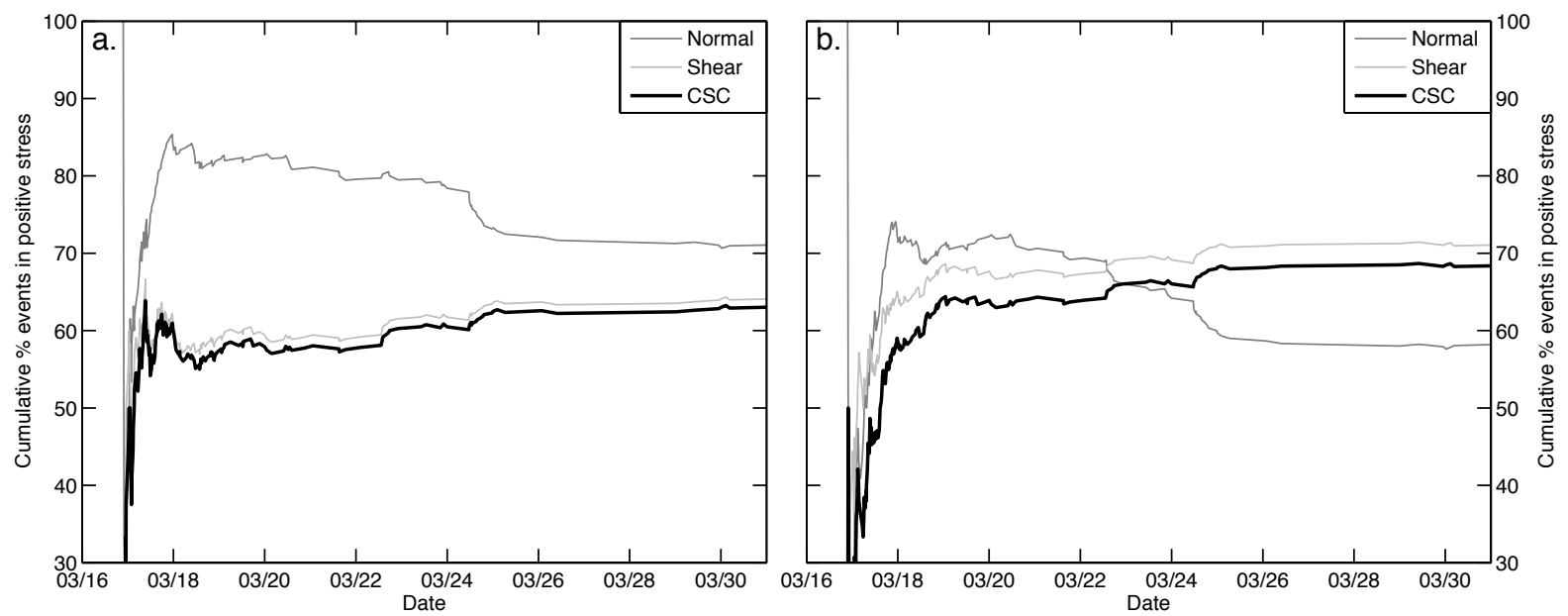

Figure DR9. Cumulative percentage of NonLinLoc catalog events that occur in positive stress change regions, as described above, calculated using the low-angle, north-dipping plane (a) and the high-angle, south-dipping plane (b). For each earthquake, the sign of the stress change induced only by all preceding events was evaluated, giving the cumulative percentage of events in regions of cumulative positive stress regions.

\begin{tabular}{ccccc} 
Source & $\mathrm{Mw}_{\mathrm{w}}$ & $\mathrm{M}_{0}\left(10^{19} \mathrm{Nm}\right)$ & $\begin{array}{c}\text { Nodal Plane 1 } \\
\text { Strike, dip, rake }\end{array}$ & $\begin{array}{c}\text { Nodal Plane 2 } \\
\text { Strike, dip, rake }\end{array}$ \\
\hline GEOFON-GFZ & 6.7 & 1.40 & $117,66,91$ & $294,25,87$ \\
USGS & $6.7(\mathrm{Mwc})$ & 1.32 & $141,70,104$ & $286,24,57$ \\
USGS & $6.5(\mathrm{Mwb})$ & 0.81 & $127,74,108$ & $258,24,44$ \\
USGS & $6.7(\mathrm{Mww})$ & 1.59 & $126,74,98$ & $277,18,63$ \\
This work & 6.1 & 0.15 & $129,58,89$ & $310,32,91$ \\
Average & & & $128,68,98$ & $285,25,68$
\end{tabular}

Table DR1. Reported moment tensor solutions provided by GEOFON, USGS and our own work. We used nearfield waveforms, which are dominated by high frequencies. In contrast, the USGS moment magnitude was derived from a centroid moment tensor inversion of intermediate- and long-period body- and surface-waves at teleseismic distances ( $\sim 30$ to $\sim 90$ degrees). Thus, a significant amount of the energy released by this event is being carried in the low frequency part of the waveforms and cannot be retrieved in our results, giving a lower estimated moment than the teleseismic methods. 


\section{REFERENCES CITED}

Allmendinger, R., González, G., Yu, J., Hoke, G., and Isacks, B., 2005, Trench parallel shortening in the Northern Chilean Forearc: Tectonic and climatic implications. Geological Society of American Bulletin, v. 117, 1/2, p. 89-104.

Allmendinger, R.W., González, G., 2010, Neogene to Quaternary Tectonics of the Coastal Cordillera, northern Chile: Tectonophysics, v. 495, p. 93-110, doi:10.1016/j.tecto. 2009.04.019.

Ekström, G., Nettles, M., and Dziewónski, A. M., 2012, The Global CMT Project 20042010: centroid-moment tensors for 13,017 earthquakes: Physics of the Earth and Planetary Interiors, v. 200-201, p. 1-9.

Hayes, G.P., Wald, D.J., and Johnson, R.L., 2012, Slab1.0: A three-dimensional model of global subduction zone geometries: Journal of Geophysical Research, v. 117, B1, B01302, doi:10.1029/2011JB008524.

Husen, S., Kissling, E., Flueh, E., and Asch, G., 1999, Accurate hypocentre determination in the seismogenic zone of the subducting Nazca Plate in northern Chile using a combined on-/offshore network: Geophysical Journal International, v. 138, no. 3, p. 687-701, doi: 10.1046/ J.1365-246X.1999.00893.X.

King, G.C., Stein, R.S., Lin J., 1994. Static stress changes and the triggering of earthquakes: Bulletin of the Seismological Society of America, v. 84, p. 935-953.

Kisslinger, C., Bowman J., and Koch, K., 1982, Determination of the focal mechanisms from $(S V / P)$ amplitude ratios at small distances: Physics of the Earth and Planetary Interiors, v. 30, p. $172-176$.

Kostrov, V.V., 1974, Seismic moment and the energy of earthquakes and seismic flow of rock, Izvestiya Academy of Science USSR Physics of the Solid Earth, v. 1, p. 23-44 (English translation).

Lomax, A.J., Virieux, P., Volant, P., Berge, C., 2000, Probabilistic earthquake location in 3D and layered models: Introduction of a Metropolis-Gibbs method and comparison with linear locations, in Thurber, C.H., Rabinowitz, N., eds., Advances in Seismic Event Location: Amsterdam, Springer, p. 101-134.

Lüth, S., 2000, Results of wide-angle investigations and crustal structure along a traverse across the central andes at 21 degrees south, Berliner Geowissenschaftliche Abhandlungen, Band 37, Reihe B, Institute of Geology, Geophysics and Geoinformatics, Free University of Berlin, Berlin-Germany.

Meade, B.J., 2007, Algorithms for the calculation of exact displacements, strains, and stresses for triangular dislocation elements in a uniform elastic half space: Computers and Geosciences, v. 33, p. 1064-1075. 
Snoke, J.A., 2003, FOCMEC: FOCal MEChanism determinations, in Lee, W.H.K., Kanamori, H., Jennings P.C., and Kisslinger, C., eds., International Handbook of Earthquake and Engineering Seismology: San Diego, Academic Press, Chapter 85.12.

Sokos, E., and Zahradník, J., 2008, ISOLA: A Fortran code and Matlab GUI to perform multiple-point source inversion of seismic data, Computers and Geosciences, v. 34, p. 967-977, doi:10.1016/j.cageo.2007.2007.005.

Waldhauser, F., Ellsworth, W.L., 2000, A Double-Difference Earthquake Location Algorithm: Method and Application to the Northern Hayward Fault, California: Bulletin of the Seismological Society of America, v. 90, p. 1353-1368.

Wells, D. L., and Coppersmith, K. J., 1994, New empirical relationships among magnitude, rupture length, rupture width, rupture area, and surface displacement: Bulletin of the Seismological Society of America, v. 84, p. 974-1002. 